
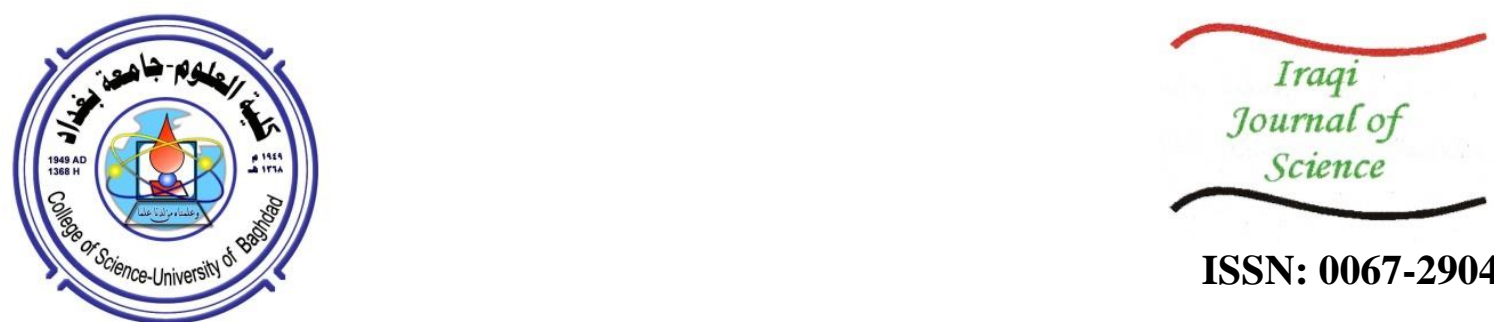

ISSN: 0067-2904

\title{
Adsorption Isotherm of Carbon Microparticles Prepared from Pumpkin (Cucurbita maxima) Seeds for Dye Removal
}

\author{
Asep Bayu Dani Nandiyanto ${ }^{1, *}$, Siti Nur Hofifah ${ }^{1}$, Hilma Tahsilul Inayah ${ }^{1}$, Ira Fitri \\ Yani $^{1}$, Silmi Ridwan Putri ${ }^{1}$, Siti Saffanah Apriliani ${ }^{1}$, Sri Anggraeni ${ }^{1}$, Dian Usdiyana ${ }^{1}$, Ali \\ Rahmat $^{2}$ \\ ${ }^{1}$ Fakultas Pendidikan Matematika dan Ilmu Pengetahuan Alam, Universitas Pendidikan Indonesia, Bandung, \\ Indonesia. \\ ${ }^{2}$ The United Graduate School of Agricultural Science, Gifu University, Gifu, Japan.
}

Received: 5/6/2020

Accepted: 16/8/2020

\begin{abstract}
This study aims to evaluate the adsorption isotherm of carbon microparticles prepared from pumpkin (Cucurbita maxima) seeds for adsorbing curcumin (as a model of dye). The results were derived and compared using the kinetics approach based on several standard adsorption isotherm models, namely the Langmuir, Temkin, Freundlich, and Dubinin-Radushkevich models. The second aim is to evaluate the effects of carbon particle size (from 100 to $1000 \mu \mathrm{m}$ ) on the adsorption characteristics. The experimental results showed that the adsorption on the surface of carbon microparticles occurred in monolayer with a physical phenomenon. This is because the active areas are located only on the outer surface of carbon and no surface structure in the carbon is available. This is confirmed by the fact that the produced carbon has less porosity and the pores themselves are mostly produced from the release of inorganic contents during carbon synthesis, while the amount of inorganic content is very less. The confirmation of the adsorption profile was also achieved by testing various sizes of carbon microparticles. Smaller particles have direct impacts on the improvement of adsorption capacity, which is due to the existence of a larger surface area, a larger number of adsorption sites, and additional cooperative adsorption, i.e. adsorbate-adsorbate interaction. Understanding the adsorption phenomena occurring on carbon particles is useful for further developments and applications, such as those of catalysts and adsorbents, especially concerning the production of carbon materials from organic waste.
\end{abstract}

Keywords: Carbon; Pumpkin; Adsorption isotherm; Langmuir; Monolayer

\section{Introduction}

Boosting the industrial sector commonly promotes environmental pollution [1]. Substances such as dyes usually exist as byproducts in the effluent, especially when industries work on textiles, leather, paper, printing, and cosmetics. Dyes are organic compounds that can colorize other substances [2]. When dyes are disposed of directly in a landfill or river, problems are created. Outlets become of colored water, hindering light penetration, deterring oxygen content, and destroying the river ecosystem. Several methods have been developed to reduce dyes in wastewater, one of which is via adsorption using carbon material [3-5].

Carbon is classified as the fourth most abundant element in the universe [6, 7]. In industry, due to its excellent performance, carbon is used in a wide range of applications [8]. Some of these applications 
include carbon used for water purification agents, gas purification agents, management of various wastes, and even for absorbing mining products.

To produce carbon, organic waste can be used as a prospective raw materials, such as rice husks and rice straws [1, 2, 9-11], orange peels [12], dragon fruit peels [13], pumpkin seed shells [8, 14], mangosteen peels[15], pineapple peels[16], tea leaves[17], walnut shells[18], palm shells[19], coconut shells[20], hazelnut shells[21], date stones[22], and almond shells[23]. The use of waste offers important solutions for environmental problems since it transforms waste into useful products [15].

One of the unconsidered types of waste is pumpkin seeds. Pumpkin is one of the most product commodities in the world [24]. Pumpkin is consumed without seeds, which are disposed of without further concerns. Although pumpkin seeds can be used for additional components in some types of bread, appetizer, oil, and flour, due to their advantages of having high dietary fiber levels, antioxidant and anthelmintic effects, as well being a good protein source [25], the shells of seeds may be the main reason for the problem of solid waste. When pumpkin seeds are disposed of directly, they can grow as weeds on the farm. When they are decomposed, a bad smell is created [26]. Thus, understanding the strategy for transforming pumpkin seeds into useful, such as carbon, materials is important for solving the issues of the increased amount of pumpkin seeds waste, especially in Indonesia. Pumpkin seeds are easily converted into carbon because they contain fewer inorganic components (less than $2 \%$ ) (Table 1).

Table 1- Chemical composition of pumpkin seeds, adopted from the literature [27, 28].

\begin{tabular}{|c|c|c|}
\hline \multirow{2}{*}{ Component } & \multicolumn{2}{|c|}{ Composition based on literature } \\
\hline & Rezig et al. [28] & Alfawaz [27] \\
\hline Moisture $^{\mathrm{a}}$ & $8.46+0.62$ & \\
\hline Crude oil $^{\text {a }}$ & $31.57 \pm 3.71$ & $27.83 \pm 0.91$ \\
\hline Crude protein $^{\mathrm{a}}$ & $33.92 \pm 3.16$ & $39.25 \pm 0.66$ \\
\hline Crude fiber $^{\mathrm{a}}$ & $21.97 \pm 4.32$ & $16.84 \pm 0.81$ \\
\hline Total ash $^{\text {a }}$ & $3.97 \pm 0.02$ & $4.59 \pm 0.16$ \\
\hline Total sugars $^{\text {a }}$ & $0.11+0.08$ & \\
\hline Carbohydrate $^{\mathrm{a}}$ & & $11.48 \pm 2.53$ \\
\hline Copper $(\mathrm{Cu})^{b}$ & $36.66 \pm 4.93$ & $0.30 \pm 0.05$ \\
\hline Zinc $(\mathbf{Z n})^{b}$ & $25.19+0.63$ & $1.09 \pm 0.06$ \\
\hline Iron $(\mathbf{F e})^{b}$ & $15.37 \pm 0.87$ & $13.66 \pm 1.60$ \\
\hline Manganese (Mn) ${ }^{b}$ & $3.42 \pm 0.76$ & \\
\hline Magnesium (Mg) ${ }^{b}$ & $146.13+9.91$ & $364.43+32.88$ \\
\hline Sodium $(\mathbf{N a})^{b}$ & $356.75 \pm 18.43$ & $68.58 \pm 16.85$ \\
\hline Calcium (Ca) ${ }^{b}$ & $271.89 \pm 24.81$ & $139.70 \pm 4.19$ \\
\hline Potassium $(K)^{b}$ & $886.56 \pm 16.34$ & $753.11 \pm 33.29$ \\
\hline Phosphorus (P) ${ }^{b}$ & $824.53 \pm 21.38$ & $1036.82 \pm 4.72$ \\
\hline
\end{tabular}

Note: ${ }^{1}$ unit in \%w/w; and ${ }^{\mathrm{b}}$ unit in $\mathrm{mg} / 100 \mathrm{~g}$ of dry weight pumpkin seeds.

The objective of this study is to analyze the adsorption isotherm of carbon microparticles produced from pumpkin seed waste. Even though many researchers have been working on the use of organic wastes and transforming them into carbon material [5], less reports presented the adsorption isotherm, especially when using pumpkin waste as the carbon source. The adsorption ability of carbon was studied using several standard adsorption isotherm models: Langmuir, Freundlich, Temkin, and Dubinin-Radushkevich models. The second purpose of this work is to evaluate the effects of carbon particle size (from 100 to $1000 \mu \mathrm{m}$ ) on the adsorption isotherm. Particle size relates to the number of adsorption site areas [29]. Indeed, understanding this parameter leads to predicting the adsorption phenomena occurring on carbon particles and provides suggestions for further applications, such as those of catalysis and adsorption, using carbon produced from pumpkin seeds. This study also employed curcumin as a model of dye because it has an ideal molecular size of less than $1.4 \mathrm{~nm}$ [11]. Thus, it can be used for predicting and describing other types of organic dyes regarding the adsorbentadsorbate interaction, since the molecular sizes of most dyes are within this size range.

Adsorption Isotherm Models Used in This Study

The illustration of adsorption is shown in Figures-1(a) and (b), which explain monolayer and 
multilayer adsorption models, respectively.

To support the explanation of the adsorption process illustrated in Figure 1, Figure 2 shows the illustration of chemical and physical adsorption. Physical adsorption, as shown in Figure 2(a), is an adsorption that has a weak tensile strength (Van Der Waals force). The adsorption process does not involve an energy that exceeds $80 \mathrm{~kJ} / \mathrm{mol}$, and the adsorbate can move from one adsorption site to another (the adsorption process is not at a specific adsorption site). Chemical adsorption, as shown in Figure 2(b), is an adsorption process that has a strong attractive force, involving energy of 600-800 $\mathrm{kJ} / \mathrm{mol}$. In the chemical adsorption, the energy can be generated from chemical bonds, interfering a condition in the sharing electrons between the adsorbate and the adsorbent molecules [30].

This study used four types of adsorption isotherm models: Freundlich, Langmuir, Temkin, and Dubinin-Radushkevich models.

The Freundlich adsorption isotherm model is the most widely used non-linear adsorption model, which represents multilayer adsorption with a heterogeneous energetic distribution from the active site on the adsorbent [31]. This model also calculates the interactions between the adsorbed molecules [32]. The adsorption energy is a function of the adsorption process on the adsorbent, which is expressed by equation (1) [23]:

$\log q_{e}=\log k_{f}+\frac{1}{n} \log C_{e}$

where $q_{e}$ is the amount of dye adsorbed per gram at equilibrium $(\mathrm{mg} / \mathrm{g}), k_{f}$ is the Freundlich constant as the estimated indicator of adsorption capacity, and $C_{e}$ is the equilibrium concentration of adsorbate $(\mathrm{mg} / \mathrm{L}) . n$ is the adsorption intensity, which can predict the phenomena during the adsorption process, as follows [9]:

(i) $\quad n<1$ is for the chemical adsorption (see Figure 2(b)).

(ii) $\quad n=1$ is for the linear adsorption (adsorption depends on the amount and concentration of the dye adsorbed. It can be a combination of chemical and physical adsorption processes).

(iii) $\quad n>1$ is for the physical adsorption (see Figure 2(a)).

(iv) $1 / n<1$ is for the normal adsorption (can be controlled under certain conditions).

(v) $1 / n>1$ is for the cooperative adsorption.

(vi) If $1 / n$ is near to zero, where the surface of the adsorbent is more heterogeneous.

The Langmuir model explains quantitatively the formation of the monolayer adsorption model on the outer surface of the adsorbent. The Langmuir isotherm model also assumes the adsorption on homogeneous surfaces without interactions between the adsorbate molecules. No transmigration from the adsorbates happens during the adsorption process. The Langmuir model is represented by equations (2) and (3)[31]:

$$
\frac{1}{q_{e}}=\frac{1}{q_{\max } K_{L}} \frac{1}{C_{e}}+\frac{1}{q_{\max }}
$$

$$
R_{L}=\frac{1}{1+K_{L} C_{e}}
$$

where $K_{L}$ is the constant of the Langmuir model and $q_{\max }$ is the monolayer adsorption capacity $(\mathrm{mg} / \mathrm{g})$. $R_{L}$ is the adsorption factors, describing the following conditions [11]:

(i) $\quad R_{L}>1$ is for the unfavorable adsorption process (encouraging desorption).

(ii) $\quad R_{L}=1$ is for the linear adsorption process (adsorption isotherms depend on the amount and concentration of the adsorbed).

(iii) $\quad R_{L}=0$ is for the irreversible adsorption process (too strong adsorption).

(iv) $0<R_{L}<1$ is for the favorable adsorption process (adsorption can be controlled under certain conditions).

The Temkin model contains a factor that explicitly takes into account the adsorbent-adsorbate interactions. The model is used to calculate the heat of the sorption process [33]. By assuming very low concentrations of adsorbates, the heat of adsorption is expressed by equation (4):

$$
q_{e}=B_{T}\left(\ln C_{e}\right)+\left(B_{T} \ln A_{T}\right)
$$


where $A_{T}$ is the equilibrium constant. $B_{T}$ is the Temkin's isotherm constant, where:

(i) $\quad B_{T}<8 \mathrm{~kJ}$ shows the physical adsorption.

(ii) $\quad B_{T}>8 \mathrm{~kJ}$ shows the chemical adsorption.

The Dubinin-Radushkevich model is generally applied to regulate the mechanism of the process and assumes the occurrence of the adsorption process on homogeneous and heterogeneous surfaces [23], which is expressed by equation (5):

$$
\ln q_{e}=\ln q_{s}-(\beta \varepsilon)^{2}
$$

where $\beta$ is the Dubinin-Radushkevich isotherm constant related to the average free adsorption energy per mol of adsorbate, $q_{s}$ is the saturation capacity of theoretical isotherms, and $\varepsilon$ is the Polanyi potential associated with the equilibrium condition. This model is estimated by equations (6) and (7):

$$
\begin{aligned}
& \varepsilon=R T \ln \left[1+\frac{1}{C_{e}}\right] \\
& E=\frac{1}{\sqrt{2 \beta}}
\end{aligned}
$$

where $T$ is the absolute temperature $(\mathrm{K})$ and $R$ is the Boltzmann gas constant $(8.314 \mathrm{~J} / \mathrm{mol} . \mathrm{K}) . E$ is the energy value used for predicting the type of adsorption, where:

(i) $E<8 \mathrm{~kJ} / \mathrm{mol}$ is for the physical adsorption.

(ii) $E>8 \mathrm{~kJ} / \mathrm{mol}$ is for the chemical adsorption.

The abovementioned models were then calculated for obtaining the adsorption efficiency ( $\% E$ ), which is measured using equation (8) [34]:

$$
\% E=\left(\frac{C_{o}-C_{e}}{C_{o}}\right) \times 100 \%
$$

where $C_{o}$ is the initial concentration of the adsorbate $(\mathrm{mg} / \mathrm{L})$.

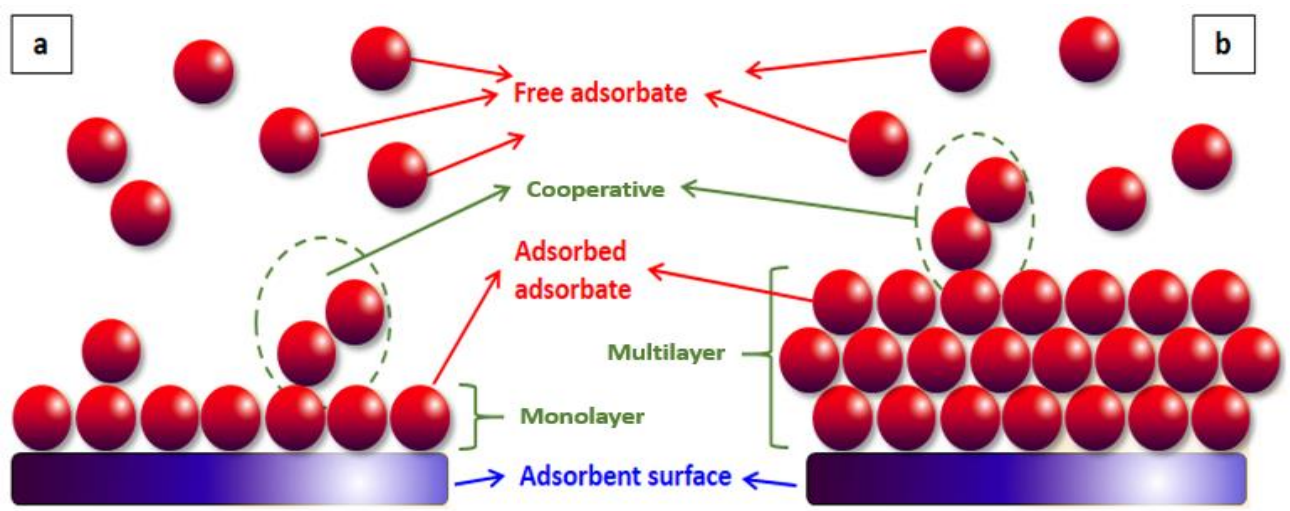

Figure 1- Illustration of the adsorption process under monolayer (a) and multilayer (b) states.

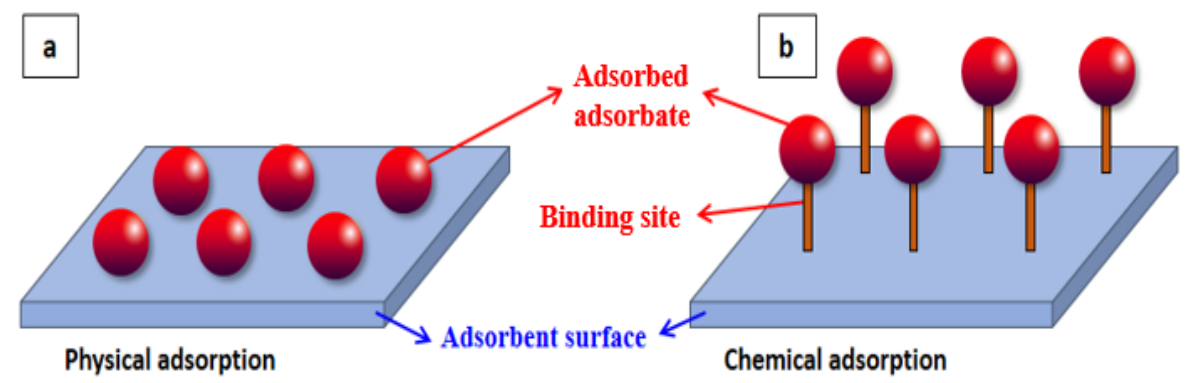

Figure 2- Illustration of the interaction between adsorbate and adsorbent surface: (a) physical and (b) chemical adsorption. 


\section{Materials and Methods}

For the preparation of carbon, pumpkin (Cucurbita maxima; taken from Lembang, Indonesia) seeds were put into the carbonization apparatus at $250^{\circ} \mathrm{C}$ for 2 hours at atmospheric conditions. Before it is exposed to the carbonization process, pumpkin seeds were washed to remove impurities, dried at $100^{\circ} \mathrm{C}$ to remove physically adsorbed water, and milled using a saw-milling apparatus to create a larger surface area for the conversion into carbon material. The carbonized pumpkin seeds were then put into the saw-milling process for re-grounding the particles to obtain carbon microparticles. Detailed procedure for the saw-milling process is explained in our previous study [35].

The prepared carbon microparticles were placed into the sieve test apparatus (Rumah Publikasi Indonesia, Indonesia; hole sizes of $2000,1000,500,200,125,100,74$, and $55 \mu \mathrm{m}$ ) to achieve the specific sizes, as well as size distribution, of the particles. The carbon microparticles with specific sizes were then washed using a centrifugation process (TG16WS High-Speed Benchtop Centrifuge, Zhengzhou Hepo International Trading, Co., Ltd., China; 11,000 rpm for 5 minutes; washed by ultrapure water) for removing inorganic components.

Several characterizations were conducted, including Fourier Transform Infrared (FTIR, FTIR4600, Jasco Corp, Japan) for analyzing chemical components of the sample and digital microscopy (BXAW-AX-BC, China) for analyzing particle size and morphology.

The adsorption isotherm test was conducted by mixing $0.05 \mathrm{~g}$ of the prepared carbon microparticles with specific sizes (i.e. 200, 500, and $1000 \mu \mathrm{m}$ ) with $100 \mathrm{~mL}$ of curcumin solution (concentrations of 10,30 , and $50 \mathrm{ppm}$ in aqueous solution) in a batch-typed adsorption apparatus (a $400-\mathrm{mL}$ borosilicate batch glass equipped with a magnetic stirrer (Rumah Publikasi Indonesia, Indonesia; $1000 \mathrm{rpm}$ )) for 20 minutes at room temperature and atmospheric pressure conditions. Curcumin solution was obtained from the extraction process of Turmeric (Curcuma Longa; obtained from a local market in Bandung, Indonesia) using a similar method described in our previous study [36]. Since curcumin is reactive to light and oxygen, the adsorption process was conducted in a closed system and free of light. The adsorption profile was obtained by taking a sample $(2-3 \mathrm{~mL})$ every 5 minutes from the mixing solution using a syringe filter (pore size of $220 \mathrm{~nm}$ ). The sample was then measured using Visible Spectroscopy (Model 7205; JENWAY; Cole-Parmer; AS) at a wavelength in the range of 200-600 nm. The spectroscopy data were plotted and calculated using the Beer law analysis, following the same plotting procedure described in our previous study [36]), and compared with the standard adsorption isotherm models of Freundlich, Langmuir, Temkin, and Dubinin-Radushkevich.

\section{Results and Discussion}

The microscopic image of the prepared carbon microparticles presented in Figure 3a shows that the particle sizes were in the range of 55-2000 $\mu \mathrm{m}$. The particle sizes were confirmed by the results obtained from the sieve test shown in Figure 3b, in which the particle sizes were in the range of 200$1000 \mu \mathrm{m}$ and the mean particle size was $195 \mu \mathrm{m}$.

Figure 4 shows the FTIR analysis results of carbon particles with various sizes. To ensure the formation of carbon from pumpkin seeds, the results were also supported by the analysis of dried pumpkin seeds (dried at $70^{\circ} \mathrm{C}$ ), as-carbonized pumpkin seeds (Processed at $250^{\circ} \mathrm{C}$ ), and standard carbon particles properties from the literature $[2,37]$. The FTIR results of all carbon samples have identical peaks and patterns, confirming the successful conversion of carbon from waste material. The FTIR analysis detected four strong peaks: $1225,1600,2845$, and $2970 \mathrm{~cm}^{-1}$, corresponding to aromatic $\mathrm{C}-\mathrm{H}$; conjugated $\mathrm{C}=\mathrm{C}$ in olefin structure and alkene; symmetric $\mathrm{C}-\mathrm{H}$; and asymmetric alkyl, respectively [38]. Organic components were transformed into carbon material during the carbonization process $[2,10,39]$. Inorganic component peaks and patterns were not detected in the FTIR analysis, since the amount of inorganic components is too small (as presented in Table 1). 

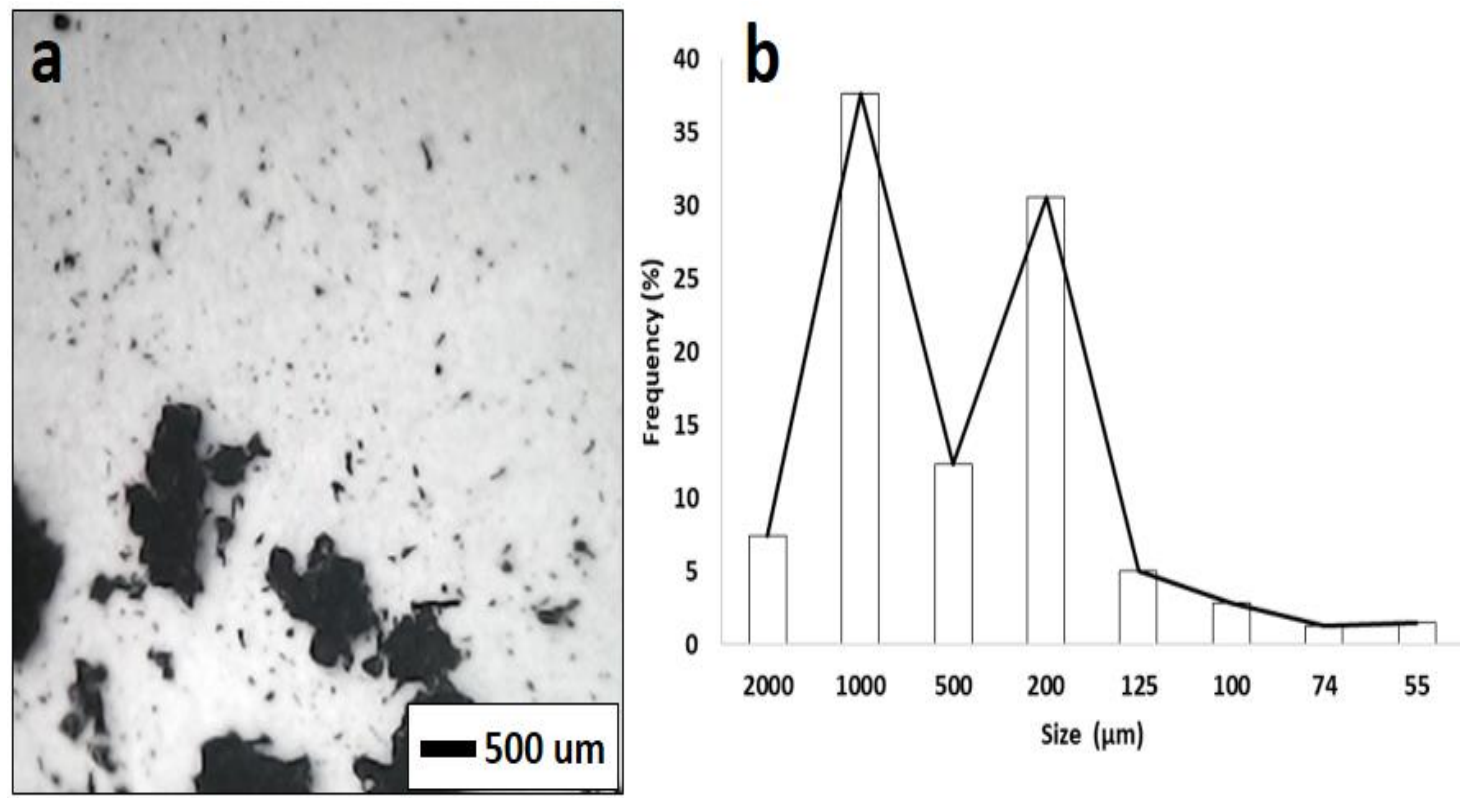

Figure 3- Particle size analysis results of carbon particles prepared from pumpkin seed waste: (a) microscope image and (b) particle size distribution.

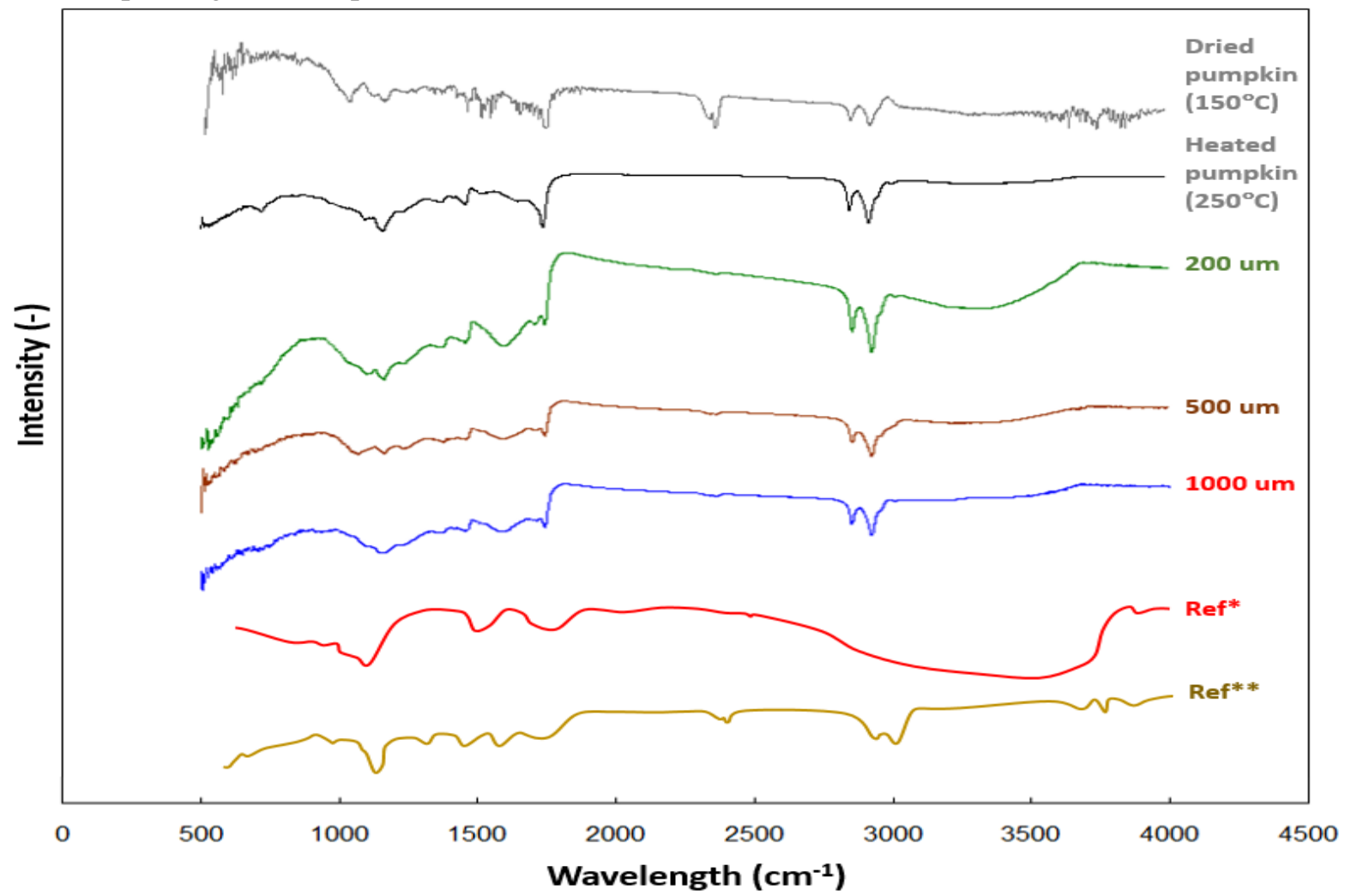

Figure 4- The FTIR analysis results of carbon particles prepared from pumpkin seeds with with various sizes. Ref* and Ref** are data extracted from references [2] and [37], respectively.

The FTIR analysis results of pumpkin seeds dried at $70^{\circ} \mathrm{C}$ and carbon particles prepared from pumpkin seeds(carbonized at $250^{\circ} \mathrm{C}$ ) with various sizes. Ref* and Ref** are data extracted from references [2] and [37], respectively.

Figures 5(a), (b), (c), and (d) show the results of the adsorption analyses using Freundlich, Langmuir, Temkin, and Dubinin-Radushkevich models, respectively. $R^{2}$ values for the linearized curves are also presented in Figure 5. The adsorption parameters gained from the plotting analysis are presented in Table 2. 
The results showed that the highest values of $R^{2}$ in all samples are for the Langmuir model, confirming that the present adsorption has a monolayer structure.

Since pumpkin seeds have less inorganic content (less than 3\%; see Table 1), the formed pores will be in a microporous structure (less than $2 \mathrm{~nm}$ ) [2], making them relatively inactive for the adsorption of organic molecules due to the problems in molecule penetration [40]. As a consequence, the adsorption occurs on the surface of the adsorbent homogenously with a thin monolayer structure [41]. The adsorbed adsorbates then disturb and prevent further adsorption processes from the other free adsorbates.

The results of the adsorption parameters listed in Table 2 show that the characteristics of the adsorption depend on the size of the particles. The adsorption profile can be divided into two size ranges: lower than $200 \mu \mathrm{m}$ and higher than $200 \mu \mathrm{m}$. An illustration of the adsorption profile based on particle size is depicted in Figure 6.

When carbon particles have sizes of less than $200 \mu \mathrm{m}$, the adsorption characteristics follow a monolayer, as confirmed by the Langmuir model. Then, Dubinin-Radushkevich and Temkin models verified that the adsorbate was physically attached to the surface of the adsorbent. Although the Freundlich model showed that the process is a chemical adsorption, this result can be neglected since it has less $R^{2}$ value as compared to those of the Dubinin- Radushkevich and Temkin models. The Freundlich model also showed cooperative adsorption, confirming the existence of adsorbateadsorbate interaction. The main reason for such interaction is that the particles themselves are too small, making them easily aggregated.

Regarding particles with sizes of larger than $200 \mu \mathrm{m}$, identical adsorption profiles were found, as shown in particles with sizes of 500 and $1000 \mu \mathrm{m}$ as a monolayer. The Dubinin- Radushkevich and Freundlich models confirmed that the process is conducted in a physical adsorption process. However, since the $R^{2}$ value of Temkin was lower than that of the other types of models, the Temkin model can be neglected. Different from particles with sizes smaller than $200 \mu \mathrm{m}$, the larger particles were produced in normal adsorption without any cooperative interaction among the adsorbates.

The results of the adsorption efficiency $(\% E)$ and maximum adsorption capacity $\left(q_{\max }\right)$ (Table 2) showed that increases in the adsorption sites can be achieved when reducing the adsorbent particle size. The small particles have a larger surface area, which increases the number of functional groups [29]. In addition, the adsorption efficiency of the prepared carbon microparticles is still low. For increasing the adsorption efficiency, additional carbon activation is required, which will be addressed in our future work.
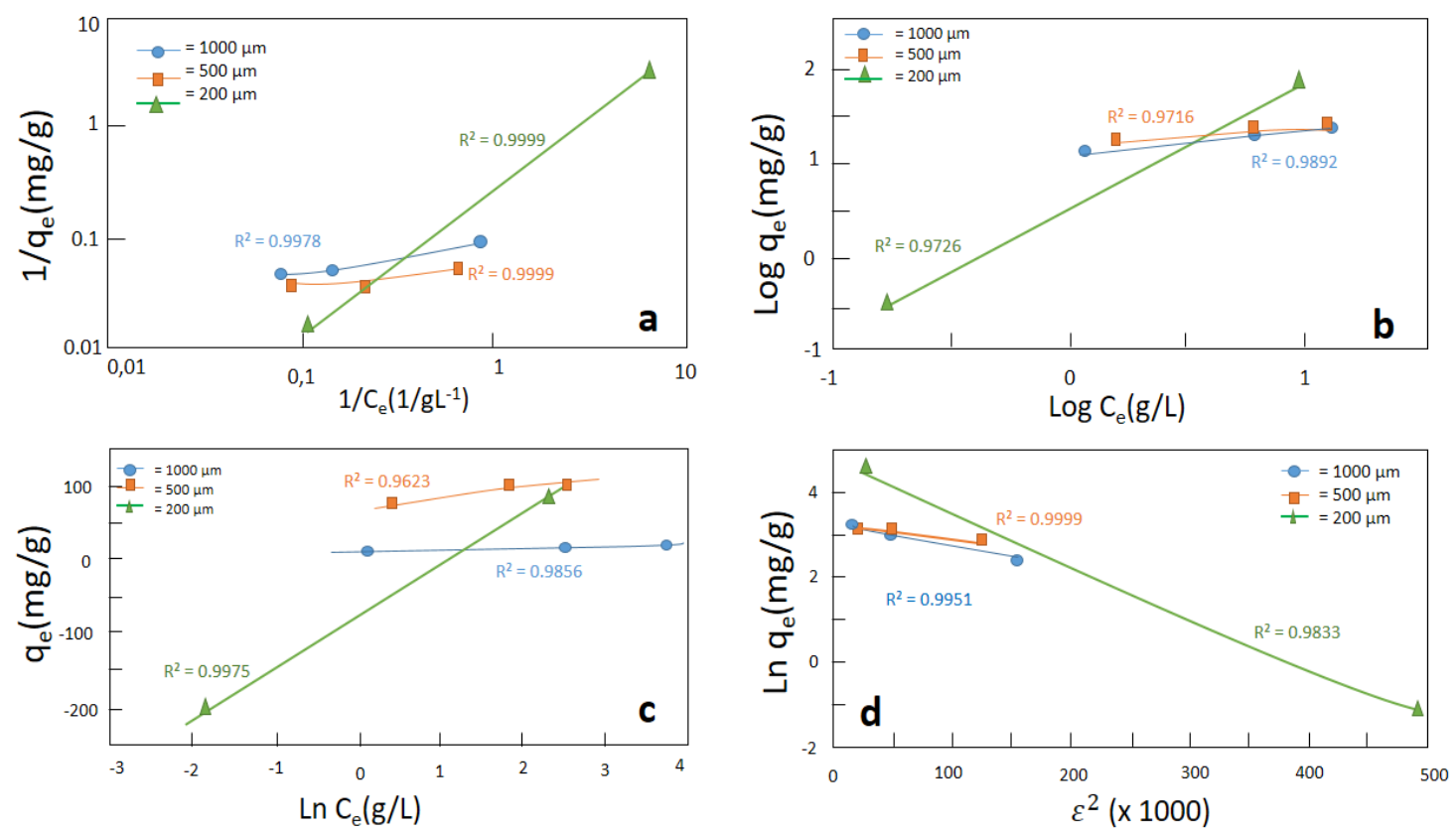

Figure 5- The plots of the experimental data compared to adsorption isotherm models: (a) Langmuir, (b) Freundlich, (c) Temkin, and (d) Dubinin - Radushkevich 
Table 2- Adsorption parameters of the Freundlich, Langmuir, Temkin, and Dubinin - Radushkevich modelsAdsorption parameters based on Freundlich, Langmuir, Temkin, and Dubinin - Radushkevich models to predict the adsorption phenomena that occur in this study

\begin{tabular}{|c|c|c|c|c|c|}
\hline \multirow{2}{*}{ Model } & \multirow{2}{*}{ Parameter } & \multicolumn{3}{|c|}{ Particle size $(\mu \mathrm{m})$} & \multirow{2}{*}{ Notes } \\
\hline & & 1000 & 500 & 200 & \\
\hline \multirow{5}{*}{ Langmuir } & $q_{\max }(\mathrm{mg} / \mathrm{g})$ & 25.6410 & 23.5294 & 32.3624 & $\begin{array}{c}\text { The maximum monolayer adsorption } \\
\text { capacity }\end{array}$ \\
\hline & $K_{L}(\mathrm{~L} / \mathrm{mg})$ & 0.7632 & 1.4455 & 0.0594 & Langmuir adsorption constant \\
\hline & $R_{L}$ & 0.1677 & 0.0968 & 0.724 & $\begin{array}{c}0<R_{L}<1 \text { indicates favorable } \\
\text { adsorption }\end{array}$ \\
\hline & $\% E$ & 78 & 78 & 76 & Adsorption efficiency \\
\hline & $R^{2}$ & 0.9978 & 0.9999 & 0.9999 & The correlation coefficient \\
\hline \multirow[t]{4}{*}{ Freundlich } & $n$ & 3.4083 & 6.2539 & 0.8126 & $\begin{array}{c}n<1 \text { defines adsorption with } \\
\text { chemical process } \\
n>1 \text { defines adsorption with physical } \\
\text { process }\end{array}$ \\
\hline & $1 / n$ & 0.2934 & 0.1599 & 1.2305 & $\begin{array}{c}1 / n<1 \text { indicates a normal adsorption } \\
1 / n>1 \text { implies cooperative } \\
\text { adsorption }\end{array}$ \\
\hline & $k_{f}(\mathrm{mg} / \mathrm{g})$ & 11.6735 & 15.3214 & 3.0318 & The Freundlich constant \\
\hline & $R^{2}$ & 0.9892 & 0.9716 & 0.9726 & The correlation coefficient \\
\hline \multirow{3}{*}{ Temkin } & $A_{T}(L / g)$ & 943.8144 & 1.3441 & 4.1511 & Equilibrium binding constant \\
\hline & $B_{T}(\mathrm{~J} / \mathrm{mol})$ & 78.3768 & 20.2896 & 3.3857 & $\begin{array}{c}B_{T}<8 \mathrm{~kJ} \text { indicates physical } \\
\text { adsorption } \\
B_{T}>8 \mathrm{~kJ} \text { indicates chemical } \\
\text { adsorption }\end{array}$ \\
\hline & $R^{2}$ & 0.9856 & 0.9716 & 0.9975 & The correlation coefficient \\
\hline \multirow{4}{*}{ Dubinin } & $q_{s}(\mathrm{mg} / \mathrm{g})$ & 25.4852 & 23.6414 & 70.0913 & $\begin{array}{c}\text { The maximum adsorption capacity of } \\
\text { adsorbent }\end{array}$ \\
\hline & $\beta\left(\mathrm{mol}^{2} / \mathrm{kJ}{ }^{2}\right)$ & 0.9951 & 0.9970 & 0.9889 & $\begin{array}{l}\text { The Dubinin-Radushkevich isotherm } \\
\text { saturation capacity }\end{array}$ \\
\hline & $E(\mathrm{~kJ} / \mathrm{mol})$ & 0.7088 & 0.7081 & 0.7110 & $\begin{array}{c}\text { Energy } E<8 \mathrm{~kJ} / \mathrm{mol} \text { is a physical } \\
\text { adsorption process }\end{array}$ \\
\hline & $R^{2}$ & 0.9951 & 0.9999 & 0.9833 & The correlation coefficient \\
\hline
\end{tabular}



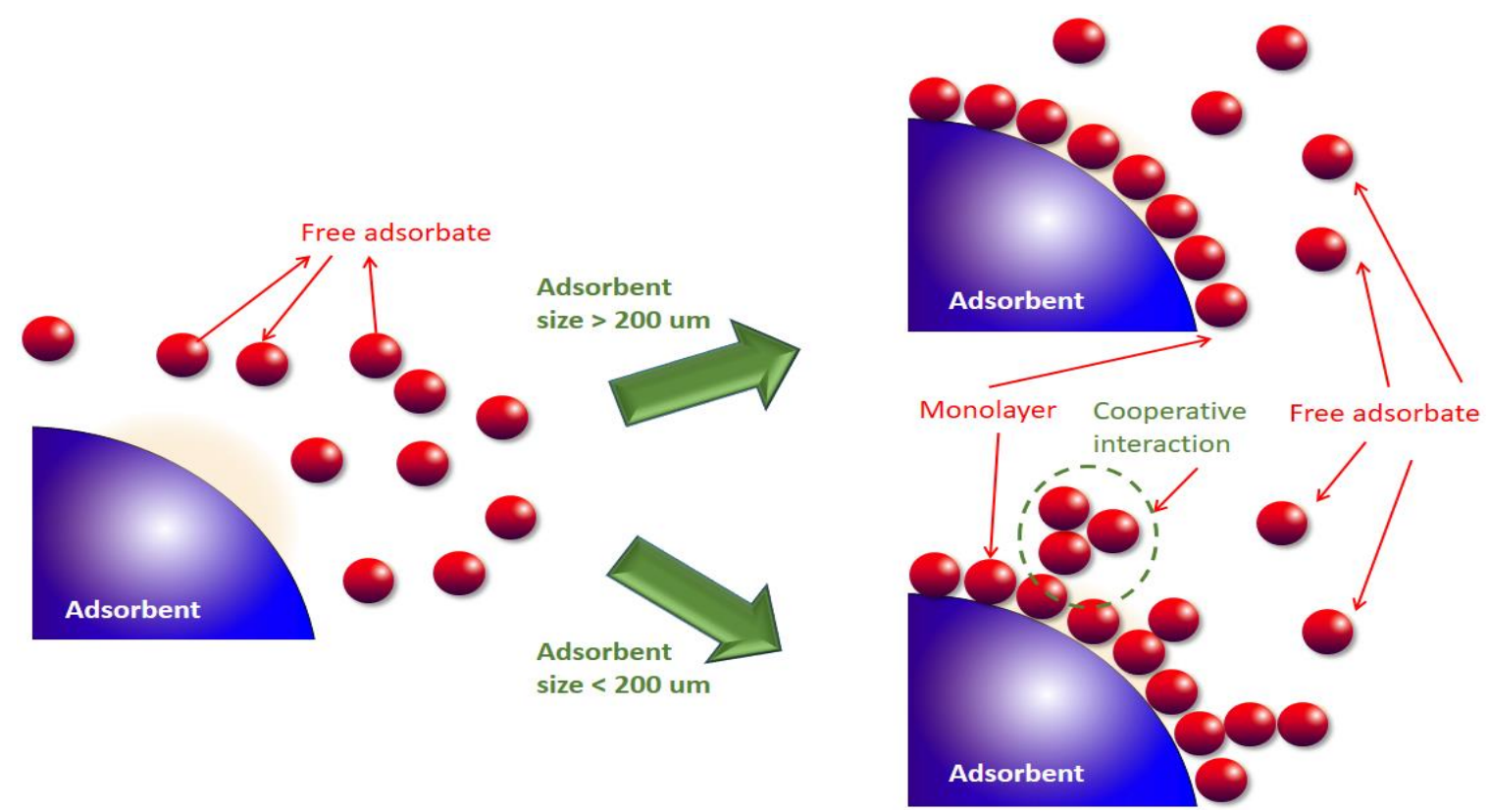

Figure 6- Proposed illustration of the adsorption profile of carbon particles in the adsorbing adsorbate molecules.

\section{Conclusions}

This study determined the adsorption isotherm of carbon microparticles prepared from pumpkin seeds based on Langmuir, Temkin, Freundlich, and Dubinin-Radushkevich models. The results showed that the adsorption on the surface of carbon microparticles occurred in monolayer with a physical phenomenon because the active areas are positioned only on the outer surface of carbon, whereas no surface structure in the carbon is available. The confirmation of the adsorption profile was also achieved by testing various sizes of carbon microparticles. Smaller particles have direct impacts on the improvement of adsorption capacity, which is due to the existence of large surface area and additional cooperative adsorption, i.e. adsorbate-adsorbate interaction. This study can be useful for further developments of carbon microparticles from organic waste material.

\section{Acknowledgments}

We are thankful to Risti Ragadhita, Rina Maryanti, and Meli Fiandini for assisting this research.

\section{Funding}

This study was funded by Ristek BRIN (Penelitian Unggulan Perguruan Tinggi (PTUPT)) and Bangdos Universitas Pendidikan Indonesia.

\section{Compliance with ethical standards}

1) Conflict of interest: Authors declare that they have no conflict of interest.

2) Ethical approval: This article does not contain any studies with human participants or animals performed by any of the authors.

\section{References}

1. Anshar, A.M., Taba, P., Raya, I. 2016. Kinetic and thermodynamics studies the adsorption of phenol on activated carbon from rice husk activated by $\mathrm{ZnCl}$, Indonesian Journal of Science and Technology, 1(1), pp:47-60.

2. Nandiyanto, A.B.D., Putra, Z.A., Andika, R., Bilad, M.R., Kurniawan, T., Zulhijah, R., et al. 2017. Porous activated carbon particles from rice straw waste and their adsorption properties, Journal of Engineering Science and Technology, 12, pp:1-11.

3. Khuluk, R.H., Rahmat, A. 2019. Removal of methylene blue by adsorption onto activated carbon from coconut shell (Cocous Nucifera L.), Indonesian Journal of Science and Technology, 4(2), pp:229-40.

4. Al-Mammar, D.E., Mohammed, R.A. 2017. Application of surfactant for enhancing the adsorption of azo dye onto buckthorn tree wood surface, Iraqi Journal of Science, 58(4A), pp:1780-9. 
5. Salman, T.A., Ali, M.I. 2016. Potential application of natural and modified orange peel as an ecofriendly adsorbent for methylene blue dye, Iraqi Journal of Science, 57(1A), pp:1-13.

6. Yan, F., Sun, Z., Zhang, H., Sun, X., Jiang, Y., Bai, Z. 2019. The fluorescence mechanism of carbon dots, and methods for tuning their emission color: A review, Microchimica Acta, 186(8), pp:583.

7. Sharma, H.K., Xu, C., Qin, W. 2019. Biological pretreatment of lignocellulosic biomass for biofuels and bioproducts: an overview, Waste and Biomass Valorization, 10(2), pp:235-51.

8. Demiral, I., Aydın Şamdan, C., Demiral, H. 2016. Production and characterization of activated carbons from pumpkin seed shell by chemical activation with $\mathrm{ZnCl} 2$, Desalination and Water Treatment, 57(6), pp:2446-54.

9. Dada, A., Olalekan, A., Olatunya, A., Dada, O. 2012. Langmuir, Freundlich, Temkin and Dubinin-Radushkevich isotherms studies of equilibrium sorption of $\mathrm{Zn} 2+$ unto phosphoric acid modified rice husk, IOSR Journal of Applied Chemistry, 3(1), pp:38-45.

10. Sukmafitri, A., Ragadhita, R., Nandiyanto, A.B.D., Nugraha, W.C., Mulyanti, B. 2020. Effect of ph condition on the production of well-dispersed carbon nanoparticles from rice husks, Journal of Engineering Science and Technology, 15(2), pp:991-1000.

11. Ragadhita, R., Nandiyanto, A.B.D., Nugraha, W.C., Mudzakir, A. 2019. Adsorption isotherm of mesopore-free submicron silica particles from rice husk, Journal of Engineering Science and Technology, 14(4), pp:2052-62.

12. Rosas, J., Bedia, J., Rodríguez-Mirasol, J., Cordero, T. 2010. On the preparation and characterization of chars and activated carbons from orange skin, Fuel Processing Technology, 91(10), pp:1345-54.

13. Jawad, A.H., Kadhum, A.M., Ngoh, Y. 2018. Applicability of dragon fruit (Hylocereus polyrhizus) peels as low-cost biosorbent for adsorption of methylene blue from aqueous solution: kinetics, equilibrium and thermodynamics studies, Desalin Water Treat, 109, pp:231-40.

14. Okoye, A., Ejikeme, P., Onukwuli, O. 2010. Lead removal from wastewater using fluted pumpkin seed shell activated carbon: Adsorption modeling and kinetics, International Journal of Environmental Science \& Technology, 7(4), pp:793-800.

15. Haura, U., Razi, F., Meilina, H. 2017. Karakterisasi Adsorben dari Kulit Manggis dan Kinerjanya pada Adsorpsi Logam Pb (II) dan Cr (VI)-(Adsorbent Characterization from Mangosteen Peel and Its Adsorption Performance on $\mathrm{Pb}$ (II) and $\mathrm{Cr}$ (VI)), Biopropal Industri, 8(1), pp:47-54.

16. Nandiyanto, A.B.D., Girsang, G.C.S., Maryanti, R., Ragadhita, R., Anggraeni, S., Fauzi, F.M., et al. 2020. Isotherm adsorption characteristics of carbon microparticles prepared from pineapple peel waste, Communications in Science and Technology, 5(1), pp:31-9.

17. Gurten, I.I., Ozmak, M., Yagmur, E., Aktas, Z. 2012. Preparation and characterisation of activated carbon from waste tea using K2CO3, Biomass and Bioenergy, 37, pp:73-81.

18. Yang, J., Qiu, K. 2010. Preparation of activated carbons from walnut shells via vacuum chemical activation and their application for methylene blue removal, Chemical Engineering Journal, 165(1), pp:209-17.

19. Lim, W.C., Srinivasakannan, C., Balasubramanian, N. 2010. Activation of palm shells by phosphoric acid impregnation for high yielding activated carbon, Journal of Analytical and Applied Pyrolysis, 88(2), pp:181-6.

20. Cazetta, A.L., Vargas, A.M., Nogami, E.M., Kunita, M.H., Guilherme, M.R., Martins, A.C., et al. 2011. $\mathrm{NaOH}$-activated carbon of high surface area produced from coconut shell: Kinetics and equilibrium studies from the methylene blue adsorption, Chemical Engineering Journal, 174(1), pp:117-25.

21. De Haro-Del Rio, D.A., Al-Jubouri, S.M., Holmes, S.M. 2017. Hierarchical porous structured zeolite composite for removal of ionic contaminants from waste streams, Chimica Oggi-Chemistry Today, 35(3), pp:56-8.

22. Al-Jubouri, S.M., de Haro-Del Rio, D.A., Alfutimie, A., Curry, N.A., Holmes, S.M. 2018. Understanding the seeding mechanism of hierarchically porous zeolite/carbon composites, Microporous and Mesoporous Materials, 268, pp:109-16. 
23. Al-Jubouri, S.M., Holmes, S.M. 2020. Immobilization of cobalt ions using hierarchically porous 4A zeolite-based carbon composites: Ion-exchange and solidification, Journal of Water Process Engineering, 33, pp:101059.

24. Dhiman, A.K., Sharma, K., Attri, S. 2009. Functional constitutents and processing of pumpkin: A review, Journal of Food Science and Technology, 46(5), pp:411.

25. Costa, L., Tomé, P., Jardim, F., Silva, V., Castilho, E., Damasceno, K., et al. 2018. Physicochemical and rheological characterization of pan bread made with pumpkin seed flour, International Food Research Journal, 25(4), pp:1489-96.

26. Permatasari, N., Sucahya, T.N., Nandiyanto, A.B.D. 2016. Agricultural wastes as a source of silica material, Indonesian Journal of Science and Technology, 1(1), pp:82-106.

27. Alfawaz, M.A. 2004. Chemical composition and oil characteristics of pumpkin (Cucurbita maxima) seed kernels, Food Science and Agriculture, 2(1), pp:5-18.

28. Rezig, L., Chouaibi, M., Msaada, K., Hamdi, S. 2012. Chemical composition and profile characterisation of pumpkin (Cucurbita maxima) seed oil, Industrial Crops and Products, 37(1), pp:82-7.

29. Nandiyanto, A.B.D., Ragadhita, R., Oktiani, R., Sukmafitri, A., Fiandini, M. 2020. Crystallite sizes on the photocatalytic performance of submicron WO3 particles, Journal of Engineering Science and Technology, 15(3), pp:1506-19.

30. Webb, P.A. 2003. Introduction to chemical adsorption analytical techniques and their applications to catalysis, pp:Micromeritics Instrument Corp. Technical Publications, retrieved from https://www.micromeritics.com/Repository/Files/intro to chemical adsorption.pdf on July 21, 2020.

31. Chung, H.-K., Kim, W.-H., Park, J., Cho, J., Jeong, T.-Y., Park, P.-K. 2015. Application of Langmuir and Freundlich isotherms to predict adsorbate removal efficiency or required amount of adsorbent, Journal of Industrial and Engineering Chemistry, 28, pp:241-6.

32. Romero-Gonzalez, J., Peralta-Videa, J.R., Rodriguez, E., Ramirez, S.L., Gardea-Torresdey, J.L. 2005. Determination of thermodynamic parameters of $\mathrm{Cr}$ (VI) adsorption from aqueous solution onto Agave lechuguilla biomass, The Journal of chemical thermodynamics, 37(4), pp:343-7.

33. Ayawei, N., Ebelegi, A.N., Wankasi, D. 2017. Modelling and interpretation of adsorption isotherms, Journal of Chemistry, 2017, pp:3039817.

34. Al-Me'ammar, A.A., Al-Sa'adi, K.A. 2009. Adsorption studies of linear alkylbenzene sulfonate by using iraqi bentonite clays, Iraqi Journal of Science, 50(2), pp:144-51.

35. Nandiyanto, A.B.D., Andika, R., Aziz, M., Riza, L.S. 2018. Working volume and milling time on the product size/morphology, product yield, and electricity consumption in the ball-milling process of organic material, Indonesian Journal of Science and Technology, 3(2), pp:82-94.

36. Nandiyanto, A.B.D., Sofiani, D., Permatasari, N., Sucahya, T.N., Wiryani, A.S., Purnamasari, A., et al. 2016. Photodecomposition profile of organic material during the partial solar eclipse of 9 march 2016 and its correlation with organic material concentration and photocatalyst amount, Indonesian Journal of Science and Technology, 1(2), pp:132-55.

37. Nandiyanto, A.B.D. 2019. Amorphous porous carbon microparticles from lumbricus rubellus, Journal of Engineering Research, 7(Special issue October 2019), pp:13-20.

38. Nandiyanto, A.B.D., Oktiani, R., Ragadhita, R. 2019. How to Read and Interpret FTIR Spectroscope of Organic Material, Indonesian Journal of Science and Technology, 4(1), pp:97-118.

39. Fiandini, M., Ragadhita, R., Nandiyanto, A.B.D., Nugraha, W.C. 2020. Adsorption characteristics of submicron porous carbon particles prepared from rice husk, Journal of Engineering Science and Technology, 15(1), pp:022-31.

40. Nandiyanto, A.B.D., Zaen, R., Oktiani, R. 2020. Correlation between crystallite size and photocatalytic performance of micrometer-sized monoclinic WO3 particles, Arabian Journal of Chemistry, 13(1), pp:1283-96.

41. Langmuir, I. 1918. The adsorption of gases on plane surfaces of glass, mica and platinum, Journal of the American Chemical Society, 40(9), pp:1361-403. 